\title{
Goodbye Time for Employees: Exit Interviews or Routine Interviews
}

\author{
Deepanjana Varshney \\ Associate Professor, King Abdulaziz University, Jeddah, Saudi Arabia
}

\begin{abstract}
Employee exit interviews are mostly overlooked areas of employee turnover process. Exit interviews play a pivotal role in a tight labor market as well as situations of skill shortage. The primary aim of conducting exit interviews is to provide the management with vital information to help prevent the loss of other competent employees later. This research seeks to explore the different aspects of exit interview conducted in select organizations in Saudi Arabia through the interview method. The objective of the research is to examine whether the employee's self-disclosure is genuinely considered as an eye-opener for resolving issues related to attitude and organization or only the reasons for leaving as a formal procedure. Findings and future research implications are discussed
\end{abstract}

Keywords: employee, engage, Exit Interview, feedback, turnover

\section{Introduction}

The broader goal of an organization is to retain its high-value and talented employees. Nevertheless, when employees are on the verge of departing the organization, it becomes imperative to explore the deeper reasons. An exit interview is an overlooked strategic instrument of the organization whose potential has never been tapped. Retaining competent and performing employees is a significant challenge today and the human resource professionals in different organizations are proactively administering the exit interviews and surveys. Exit interviews have multiple objectives: they may convince a departing employee to reconsider and remain in the organization, trace causes for employee turnover and implement the valuable inputs to enhance organizational functioning. According to [1], the majority of the research related to exit interview has been encompassed around the organizational dimension. With the critical information derived from a properly conducted exit interview, the management can reframe and develop enriched policies and make an endeavor to retain key employees. The interview process demonstrates genuine information regarding various facets of the organization. Exit interviews are distinctive from other methods of employee information collected as they can extract the kind of vital information that the employee would not have otherwise divulged if he/she was still working in the organization.

This research aims to investigate the effectiveness of the exit interviews conducted from the perceptual viewpoint of the HR professionals of select organizations based in Saudi Arabia and also critically examine the exit interview frameworks and conditions of the respective organizations.

\section{Literature}

Exit interview in a more specific way is a private and open interaction between a company appointed person and the leaving employee to find out the reasons for the employee's imminent departure [2]. Past literature majorly focused on the validity of the exit interviews [3], the typical exit interview [4] and the organizational understanding of the exit interview communication [5]. In a way, the exit interview should be well aware of the dissatisfaction reasons and make an effort to retain the qualified employees by promising to resolve their grievances [6]. Data gathering through the exit interview is a pivotal exercise. This data concerns the future of the company and reflects the exact causes of employee intention to leave and eventually go through the quitting process [7]. The information gathered should be relevant and supportive in providing healthy, positive feedback [8]. An introspective exit interview can yield continuous comments and inputs from all sections of the organization [9]. 
Moreover, Exit interviews safeguard some impending obstacles that have the chances to take place. The relationship between the company and the departing employee should end in a professional and cordial note. The employee should not bear any ill-will or grievance about any issue, and the trade secrets and confidential resource/product/process related information should remain intact in the old organization and not disclosed elsewhere by the employee [10].

An additional issue regarding Exit interview is the biased responses employees give during the process. There are several reasons: low-interest level, anxiety related to retaliation and consequences, loss of anonymity [11]. Furthermore, the manner and timing of the exit interview can elicit the correct information [12].

The importance of Exit interviews cannot be undermined as it investigates the antecedents of turnover [13]. There have been arguments raised on the method and data gathered [14], [15], [16], and [17]. The role of the exit interview is varied regarding framework and procedure, and the management can derive information about the employment experience and the reasons for departure [18], [19], [20]. The topics discussed in the interview can cover a full gamut of reasons: views about the management and the company, work climate, group dynamics, and contentment with the job [21].

\section{Method}

Qualitative methods provide detailed information and bring an insightful understanding of the matter [22]. It is better than the questionnaire based surveys as the responses of the interviews are standard and conclusive for proper interpretation [23]. However, the cases of personal, semi-structured or unstructured interview questions are qualitative, and comparison with other departing, or departed employees can become difficult due to varied nature of questions. Qualitative methods can provide more insight, more inputs as compared to the standard questionnaire. Qualitative methods were used in this study. The use of in-depth interviews is done to unearth rooted behavior and since it also delves into the employee psychology in the organizational context [24].

In most of the cases, interviews were recorded with a voice recorder and notes taken, with the consent of the interviewee (HR professional). Structured interviews were conducted with the HR professionals from four organizations in Saudi Arabia. In all the four organizations, the HR professionals requested for anonymity hence the identities of the companies were not divulged in the paper for ethical reasons.

The areas of the research are related to

- The nature of the interview

- The kinds of questions asked during the exit interview

- Training of the interviewer

- Key issues

- Challenges faced in the interview process

- Use of the data obtained from the interview

- Improvements of the system

- Implementation of the data obtained

- Attitude surveys

- Related issues

\section{COMPANY 1:}

\section{Background:}

This company was founded in the early 90s and is into hospitality and leisure sector. In a couple of years, it expanded its activities within the Middle East, parts of Asia and Africa and Europe. The expansion plan is ambitious for the next few years. The company which had started as a partnership agreement between two people in business and with two properties now aims to reach a hundred properties.

\section{Interview Summary}

The salient aspects expressed by the Human Resource Manager can be summarized: 
- The choice and structure of the Exit interview of an employee depend on the management. The management has to arrange for the interview if they do not want the employee to leave once the resignation letter is received. Efforts are made to resolve the problems at once so that the employee stays. In contrast, if the management is not keen to retain the employee, then exit interview is conducted as a formality along with other separation processes.

- The reasons for which the employees express their intention to leave are varied, namely, family issues, salary reasons, health issues and returning to home country

- The question regarding the relationship with the supervisor is asked in a subtle manner like what did he/ she enjoy most in the company, for instance, whether there was adequate support given in the department. The employee response, however, depended on the perceived reliability of the interviewer.

- The HR manager also discussed the challenges, especially retaining a high-value employee when the resources are limited. At times the company had to bid goodbye to performing employees as there was a limitation in the budget.

- Feedback of the interview is immediately discussed with the management in case they are trying to retain the employee or else it is kept as a reference in the employee file. Usually, all suggestions cannot be implemented, only the suggestions that attract the management attention and the manager considers fruitful in changing the current situation are accepted. Data analysis is done on the valuable information on a citywide basis to identify the trends.

\section{COMPANY 2: A DIVERSIFIED GLOBAL COMPANY}

\section{Background:}

The company was built in late 1960's and almost spent fifty years doing business in Saudi Arabia. It is one of the most reputed brands in lubricants and has four business lines: oil lubricants, car servicing fuel retailing and car dealerships. The export division of the company covers more than forty countries. There are above 5000 employees employed by the company.

\section{Interview Summary}

The HR executive emphasized on the following areas:

- Intensive interaction is there between the employee and the HR department. Various aspects related to the supervisor relations, training and development opportunities and general leadership are examined in the exit interview.

- The exit interview is conducted by the recruitment manager who is also specially trained in this area. There are two formats and patterns of exit interviews, one for the regular employee and the other for the senior employee. The latter is more extensive and elaborate. The executive refused to share the details of the employee feedback due to confidential reasons but had pointed out that most of the reasons for departure were related to lack of training, development and poor supervisor relations.

- One of the challenges that the professional shared was regarding the departing employee being reluctant to sign some discussion points for fear of repercussions. Also, there is the risk that some departing employees give dishonest responses or monosyllabic replies during the interview and do not cooperate

- The exit employee feedback also revealed that financial rewards were not a factor affecting departure as the company was supposed to be a good paymaster. Additionally, the perks and perquisites were lucrative too.

- Though the interviewee did not mention of attitude surveys conducted earlier but stressed on the suggestion program on the website which the employee can fill from time to time, and a team oversees it.

Discussion about the time taken to implement the departing employee's suggestions revealed that it was done on a quarterly basis. However, the HR staff was vague about the data handling methods and analysis or the number of suggestions being accepted for implementation in a quarter. 


\section{COMPANY 3: GLOBAL FURNITURE COMPANY}

\section{Background}

It is a multinational company that designs and sells ready-to-assemble furniture, kitchen appliances, and home accessories and is a pioneer in its field.It follows the franchise system across the globe.

\section{Interview Summary}

The assistant to the HR director described the exit interview system:

- There is a questionnaire that consists of all probable areas of work environment and satisfaction level. There is a suggestion section in that questionnaire. The suggestion part is usually at the end of the questionnaire, and if the HR deems it valuable, it is conveyed to the senior manager of the department. One of the long-standing suggestions of the employees has been to convert full-time schedule to part-time schedule.

- The interviewer is usually the HR professional in the department. There is no specialized training provided to improve the skills of the interviewer.

- One of the primary reasons for leaving the company has been due to poor compensation policies as expressed by the departing employees. There were other reasons like the completion of higher studies or better job opportunities. In cases of deteriorating relations with the supervisor, most of the time the department can be changed on request.

\section{COMPANY 4:}

\section{Background}

One of the leading groups in the hospitality sector and spread across the globe (with around 600 locations), known for it has reputed brands and authentic services.

\section{Interview Summary}

- The company conducts pre-exit interviews like the majority of the cases. The human resource officer conducts the exit interview, and a general question on the human relations, work environment, and compensation are asked. When the HR manager was asked about the training given to these officers before conducting the interviews, the response was negative.

- The company assesses awards every three months based on the performances and also gives satisfactory bonuses.

- Suggestions collected from the departing employees are communicated to the proper departments. There are some suggestions collected, but the human resource professionals are unaware of what is done with the knowledge and resources collected.

- The employee evaluation of the effects related to the HR activities is collected. The departing employee's clear perception of the HR functions impacting the employment is described by him/her.

- The HR was satisfied with the system and procedure of the Exit interviews and does not analyze the productive results of the process. Nor do they face challenges in conducting the interviews.

\section{Discussion}

Turnover is inevitable and cannot be avoided, and some amount is beneficial too. The employer should accept the fact and deal professionally with the fact. The critical purpose of the exit interview is to delve into the actual reasons and systematically manage the exit process [25]. Some managers try to have a defense mechanism by avoiding the exit interviews due to several reasons mainly to conceal their lack of abilities [7].

The departing employee should be engaged in a meaningful interaction so that there is positivity and this might influence the employee to become associated with the company in any capacity in future. The interaction can be pleasant and value added if a warm ambience is created where the individual interviewee feels psychologically relaxed. Only in such an environment, the communication can be mutually and professionally satisfying [21]. The interview responses of the large furniture retailer support the private, closed space where the interviews are regularly conducted in a low-key atmosphere: 
"We have specially designed a private and cozy space in the office to conduct the interviews in a personalized manner as it relaxes the employee in many ways."

Another point discussed has been the effectiveness of the HR professional conducting the exit interview or someone from outside appointed by the company. [26] argued that human resource managers would be seen as unbiased by the departing employees and more competent in dealing with employees and fostering a suitable climate for conducting the interview. This study is in contrast with [27] who had drawn attention to the human resource professional's perception of the employee's exit and the real reasons which are usually not similar. It becomes imperative to realize the disparity between the false or incomplete assumption of the HR professional and the real situation faced by the employee.

In most of the interviews conducted in the study, the feedback of the HR professional was taken regarding the effectiveness of the exit interviews, and all of them expressed their satisfaction with the prevailing system and did not recommend any modification or enhancement. The company should allocate resources for keeping good employees and even if the employee leaves eventually, blame should not be only put on the immediate supervisor. There is also lack of clarity with the responsibility of exit interview data collected [27]. The responses collected from the companies also reveal a complete unawareness about the purpose of the data collected and in what manner it fits into the overall pattern of organizational development processes.

Most of the responses in this area were about, "We collect the information and put in files," or "we pass it to the proper departments, but we do not know what happens after that."

This kind of responses is indeed alarming because the HR is supposed to be the strategic partner to the top management of the organization. Furthermore, if the HR professionals do not understand or come to know about the utility of the data collected, then questions can be asked about the focus on relevant data they keep on collecting throughout the year.

There has been negative criticism about the level of employee privacy being compromised through the exit interviews and that these interviews are more useful for the company perspective than the departing employee [21]. [17] has highlighted on the negative repercussions of the face to face interview because of uneven power shared between the employer and the employee, it may hinder accurate responses, and the interview can become farcical to a great extent. One should also think about the departing employee with empathy which sometimes the organization misses out. Employees sometimes are stressed as they have doubts over the privacy factors and the adverse effects in case they are candid. Another research finding is related to the responses of the employees that surprisingly vary from those given during exit process and those conducted after the process is over [28].

\section{Limitations and Future Research Implications}

The study has some limitations: only four companies had consented to the interviews, future studies should include more organizations. There should be empirical studies conducted with the leaving employees besides HR professionals if allowed. Another limitation was the immense sense of guarding exit process-related information and not disclosing data concerning exit interviews.

Future studies should cover critical areas, mainly, the gap between the perceptions of the departing employee and the HR professional in analyzing the exit interviews, the comparison between the independent third party and the HR staff's data collected through the separate interviews and the effectiveness of the behavioral competencies imparted in exit interview training programs. There should be more studies conducted using experimental variables and mixed methods

\section{Suggestions}

An exit interview is unique in many ways and explores the hidden facts through valuable communication. It is indeed a tremendous challenge to make the employee share details which he/she may not be willing to do. The right amount of time, a thoroughly capable HR professional to communicate, collect and examine data is 
required. Investigation of the reasons and factors of departure and formulating a sound plan to combat costly turnover are the dimensions that are taken into consideration. Since the communication related to the exit interview is not only limited to knowing the reasons for departure but also essential to get inputs on other important areas (compensation related information, complaint issues, benefits).

The opaque system of conducting exit interviews with the companies interviewed reveals the strong, oneman ship of the HR's role which is not recommended at all. An outsider is having the industrial expertise, psychological acumen, and scientific evaluation skills should be invited to conduct such interviews. Some employees feel stressed to share in face-to-face meetings and can manipulate information. In such situations, online interviews can minimize the reluctance.

A notable feature in the interviews was the complete complacency of the HR with the lack of training given to them. In one of the interviews the response filled with over-confidence:

"We are the HR people and know the best about employees; there is no need for training about an interview like exit." The particular response is a cause of concern and can hinder the exit interview process. The staff conducting exit interview should be meticulously trained and developed in absorbing the skills of the behavioral interviews in the Exit process. Most of the companies do not conduct attitude surveys, but there are suggestion schemes in the companies. Attitude surveys along with suggestion schemes should be used simultaneously to understand employee dissatisfaction at a minimum level.

There is a passive degree of involvement observed in the way these interviews are conducted; exit interviews are perceived to be more of a formality in the majority of the firms. A sense of proactive approach should be inculcated among the HR staff to understand its strategic importance in the long run and this can be done through rigorous training in the area of conducting exit interviews

\section{References}

[1] J. U. Duncombe, "Infrared navigation—Part I: An assessment of feasibility," IEEE Trans. Electron Devices, vol. ED-11, pp. 34-39, Jan. 1959.

[2] Yu-Shan Chien, "Communication Strategies for Exit Interviews in Business: From the Employee's Perspective," Conference, pp. 1-12, Soochow University, June 2013.

[3] Michael E. Gordon, "The Dialectics of the Exit Interview: A Fresh Look at Conversations About Organizational Disengagement," Management Communication Quarterly, Vol.25, No.1, pp.59-86, 2011. https://doi.org/10.1177/0893318910376914

[4] J.Lefkowitz and M.L. Katz, "Validity of exit interviews," Personnel Psychology, Vol.22, No.4, pp.445-455, 1969. https://doi.org/10.1111/j.1744-6570.1969.tb00345.x

[5] M.Hilb, "The standardized exit interview", Personnel Journal, Vol.57, pp.327-329, 1978.

[6] S.A. Cox and M.W.Kramer, "Communication during employee dismissals: Social exchange principles and group influences on employee exit", Management Communication Quarterly, Vol.9, No.2, pp.156-190, 1995. https://doi.org/10.1177/0893318995009002002

[7] J.G. Neal, "Staff turnover and the academic library. In Foundations in library and information science," Options for the 80s: Proceedings of the second national conference of the Association of College and Research Libraries, 17(A), 99016, 1982.

[8] M.Neil, "Exit Strategies,"ABA Journal, Vol.92, No.2, p.22-22, 2006.

[9] Rohtas Kumar, Ajay Kumar Garg, Sarang Jagdale, Jai Y Advani, "Understanding employee cycle through exit interviews: Conceptual framework ad case illustration," South Asian Journal of Management, Vol.11, No.4, October-December, 2004.

[10] Keith A. Bender and John S. Heywood, "Job satisfaction of the highly educated: the role of gender, academic tenure, and earnings," Scottish Journal of Political Economy, Vol.53, No.2, pp.253-279, March, 2006. https://doi.org/10.1111/j.1467-9485.2006.00379.x

[11] W.K.Silverman, A.M.Albano, B.M. Siebelink and P.D.A. Treffers, ADIS-C: Anxiety disorders interview schedule for DSM-IV-child version, Lisse: Swets Test Publ, 2001.

[12] R.A., Giacalone, S.B. Knouse and A. Montagliani, "Motivation for and Prevention of Honest Responding in Exit Interviews and Surveys," The Journal of Psychology, Vol.131, pp. 438 - 448, 1997.

https://doi.org/10.1080/00223989709603531 
[13] J.R. Hinrichs, "Measurement of Reasons for Resignation of Professionals: Questionnaire versus company and consultant exit interviews," Journal of Applied Psychology, Vol. 60, pp.530 - 532, 1975.

https://doi.org/10.1037/h0076915

[14] C. Mok and Y. Luk, "Exit interviews in hotels: Making them a more powerful management tool," International Journal of Hospitality Management, Vol.14, No. 2, pp. 187-194, 1995. https://doi.org/10.1016/0278-4319(95)00025-8

[15] M.A.Deery, Promotional Opportunity and Employee Turnover: A Reexamination of the Relationship, Melbourne: Victoria University of Technology, 2000.

[16] D. Feldman and B. Klaas, "The impact of exit questionnaire procedures on departing employees' self-disclosure," Journal of Managerial Issues, Vol. 11, No. 1, pp.13-26, 1999.

[17] M. Fottler, M. Crawford, J. Quintana and J. White, "Evaluating nurse turnover: comparing attitude surveys and exit interviews", Hospital \& Health Services Administration, Vol.40, No. 2, pp. 278-295, 1995.

[18] Jack J. Phillips and A.O. Connell, Managing Employee Retention - A Strategic Accountability Approach, Burlington, MA: Elsevier, 2003.

[19] J. Evans, "Exit interviews provide insight into problems", Louisiana Contractor, Baton Rouge, Vol. 55, No. 1,pp. $36,2006$.

[20] R. Rudman, Resource Management in New Zealand, Auckland: Pearson Education New Zealand Limited, 2002.

[21] R. Stone, Human Resource Management, Queensland: John Wiley \& Sons Australia, Ltd., 2005.

[22] David Williamson, "That's no way to say goodbye: Exit Interviews and Employee Turnover in New Zealand Hotels," Master thesis, Auckland University of Technology, New Zealand, 2009.

[23] D.M. Mertens, Research methods in education and psychology, 2nd ed., Thousand Oaks, CA: Sage, 2005.

[24] L. Valentine, "Making an Informed Exit", ABA Banking Journal, Vol. 97, pp.72-72, 2005.

[25] R.B. Rubin, A.M. Rubin and L.J. Piele, Communication research: Strategies and Sources, 6th ed., Belmet, CA: Wadsworth, 2005.

[26] Van Wert and I. Gregg, "An Evolving View of Exit Interviews," Americal Printer, Vol. 233, No. 6, p.40-40, Sep2004.

[27] D. Schachter, "Exit interviews can provide valuable feedback," Business Management, Vol.9, No. 7, pp. 9-10, 2005.

[28] Jo Faragher, "Why staff really leave," Personnel Today, p22-23, Jan.2008.

[29] J.P. Wanous, Organizational Entry - Recruitment, Selection, Orientation and Socialization of Newcomers, 2nd ed., New York: Addison-Wesley Publishing Company, 1992.. 